\title{
Clinical and Laboratory Studies of Dermatophytosis Affected Dogs in Correlation to Oxidative Stress
}

\author{
Nafie, T. S.; Mahmoud, M. M. ${ }^{\mathbf{1}}$ and Dina A. Abdelkhalek
}

Department of Internal medicine, ${ }^{1}$ Infectious diseases, Faculty of

Veterinary Medicine, Suez Canal University, Ismailia

E-mails: tnafie@hotmail.com, Mmostafa76@yahoo.com

dina_amin@vet.suez.edu.eg*

\section{Abstract:}

Skin diseases are one of the most common health problems in dogs. This study aimed to record the clinical and laboratory findings of dermatophytosis on dogs, with its effect on blood plasma as well as its correlation to oxidative stress.

The clinical study was conducted on two groups of dogs. The first group consisted of fourteen dogs was clinically healthy and used as a control one.

The second group consisted of sixteen dogs at different ages affected and suffering from dermatophytosis.

All dogs were subjected to clinical examination followed by special dermatological examination. Skin scrapings were examined under light microscope for detection of fungal spores. Blood samples were taken for hematological analysis and plasma samples for biochemical analysis.

Dermatophytosis affected dogs showed a highly significant decrease of hemoglobin, hematocrit, MCV values and a significant decrease in $\mathrm{RBCs}$ count and $\mathrm{MCHC}$ as well as a highly significant increase in total leukocyte counts of diseased dogs when compared to control ones

Significant differences in hematological parameters were observed in dermatophytosis affected dogs. Furthermore, Oxidative stress markers such as catalase, SOD, GPx and MDA revealed significant variations in diseased group when compared to healthy ones. A correlation between analyzed data revealed positive correlation between plasma zinc and copper levels and antioxidant enzymes as SOD, GPx in diseased dogs.

Key words: Dogs, dermatophytosis, hematological analysis, oxidative stress markers, correlation analysis 


\section{Introduction:}

Dermatophytes has a particular effect on the skin ranged from mild to severe generalized demodicosis (Muller et al., 1989). Dermatophytosis is the most common and important skin disease of dogs. It is define d as an infection of the keratinized tissues, claws, hair, and the stratum corneum caused by different species of dermatophytes (Gaskell, 1994). Moriello (2019) reported that dermatophytosis is an infectious and contagious superficial fungal skin disease of dogs. Long haired dogs are at higher risk due to hereditary factors and/or the fact that spores stick to their hairs (Moriello, 2004). Dermatophytosis is characterized clinically by alopecia, scaling, focal to multifocal circumscribed patches of skin, hair loss, broken hairs, scaling, pustules, papules, exudation, crusting, hyperpigmentation and pruritus (Birchard and Sherding, 2005). Symptoms were most commonly distributed on face, feet and tail (Outerbridge, 2006).

Laboratory diagnosis of dermatophytes The routine identification and classification of the dermatophytosis is mainly based on the clinical symptoms and the morphololgical and / or biochemical characteristic of the fungi (Gaedigk et al., 2003) involving direct microscopic examination of skin specimens followed by culture technique (liu et al., 2000).

Chronic fungal infection in dogs results in lymphocytosis and monocytosis (Stockham et al., 2003). However, Nair \& Nauriyal (2007) found no significant difference in hemoglobin level, total erythrothytic count, Packed cell volume, total leukocytic count and differential leukocytic count in fungal infection in dogs.

Sindha et al (2015) reported a significant lower of $\mathrm{Hb}, \mathrm{PCV}$, and TEC, neutrophils in cases of fungal skin diseases. While, lymphocytes and eosinophils were significantly higher.

Okayama (2005) stated that the skin is exposed to endogenous and environmental pro-oxidant agents, leading to production of harmful generation of reactive oxygen species (ROS). The author added that the resulting oxidative stress damages proteins, lipids, and DNA. Moreover, Singh et al. (2011) mentioned that oxidative stress has been implicated to play an important role in a etiopathogenesis of various infectious, inflammatory and degenerative diseases including dermatitis.

\section{Mate rials and methods:}

The clinical study was conducted on two groups of dogs of different breeds and ages. The 
first group was clinically healthy consists of fourteen dogs were used as a control group.

The second group included sixteen dogs affected with dermatophytosis out of ninety skin diseased dogs.

The study was carried in the clinic of both faculties of veterinary medicine, Suez Canal university, Ismailia, and Cairo university, Egypt. Definitive diagnosis was carried included case history, physical examination, close inspection of entire skin; skin scraping. Examination included body temperature, pulse, respiratory rate, superficial lymph nodes and inspection of both skin and skin coat according to Birchard \& Sherding (2005).

Multiple skin scrapings were taken from the periphery of the lesions on alopecic areas until oozing of blood. The collected samples were mixed with collected several drops of $10 \%$ sodium hydroxide $(\mathrm{NaOH})$ solution then gently heated and examined using light microscope for identification of spores of dermatophytes (Houston 2000). Whole blood samples were taken then sent immediately for hematological analysis to obtain complete blood pictures "by using fully automatic blood cell counter (Model: PCE-210N)" as well as and separation of plasma. Plasma was frozen at $-80^{\circ} \mathrm{c}$ for biochemical analysis.
Zinc, copper, SOD, Catalase, GPX and MDA were estimated using colorimetric test kits (BioDiagnostic Company Egypt) according to manufacturer's instructions (Hayakawa, 1961; Ventura and King, 1951; Nishikimi et al., 1972; Aebi, 1984; Paglia and Valentine, 1967 and Ohkawa et al 1979) respectively.

Statistical analysis the obtained data was analyzed using statistical program of social science (SPSS) for windows, Version 24. Values of the measured parameters were expressed as mean value \pm slandered error (S.E) and the difference between means of the two groups was determined by using one tail t- test and the significance was considered at $\mathrm{P}$ values $<0.05$ or $<0.01$. Correlation between variables was evaluated using Pearson Correlation Coefficient. The interpretation of Pearson correlation Coefficient according to (Mukaka, 2012).

\section{Results and discussion:}

The clinical investigation revealed that dermatophytosis was diagnosed in sixteen dogs $(17.77 \%)$ out of ninety dogs suffered from dermatological problems. The present study showed that the German shepherd dogs were the most affected breed among dermatophytosis infected group. 
The obtained findings were similar to that reported by Jaheen (2015) who recorded that the German shepherd dog breed was the most affected by dermatophytosis.

Physical examination of diseased dogs revealed normal mucus membrane, temperature, pulse rate and respiratory rate. The observed clinical signs of dermatophytosis appeared as a circular area of alopecia of different sizes, whitish scales and erythema. Itching was not observed in most cases. Similar findings were described by Birchard and Sherding (2005); Bond (2010) and Paterson (2019) as well as circumscribed focal or multifocal, mildly pruritic alopecic scale lesions, hair loss, papules, scales, crusts, erythema, follicular plugging.

The direct microscopic examination of hair and scales revealed endothrix and exothrix spores and hyphae of dermatophytes indicated positive dermatophytosis. The same results were reported by Liu et al. (2000); Lappin and Turnwald (2004); Moriello and Newbury (2006) and Chermette et al. (2008) who mentioned that direct microscopic examination of hair and scales reveal the presence of fungal hyphae or identify arthrospores which appear as a dense aggregates of spherical structures cover the hair shaft. Moreover,
Putriningsih and Arjentinia (2017) reported that the arthrospores were seen as a loosely clear round shape element.

Dermatophytosis affected dogs (table 1) showed a highly significant decrease of hemoglobin, hematocrit, MCV values and a significant decrease in $\mathrm{RBCs}$ count and $\mathrm{MCHC}$ values in comparison to control group. A highly signific ant increase was recorded in total leukocyte counts of diseased dogs when compared to control ones. Sindha et al (2015) reported similar results for the average values of $\mathrm{Hb}, \mathrm{PCV}$, RBCs which were significantly lower in fungal infection in diseased dogs than control. The differential leukocytic count showed a highly signific ant increase in both granulocyte and monocyte absolute values. These results agreed to those obtained by Stockham et al. (2003) who reported that chronic fungal infection in dogs characterized by monocytosis.

The biochemical findings of dogs suffered from dermatophytosis table (2) revealed no significant changes in plasma zinc levels. Similar findings were reported by Kerem et al. (2009) and Ural et al (2009) who reported no statistical differences in plasma zinc concentrations between dermatophytosis and normal 
dogs. Regarding catalase activity, a significant increase was recorded (table 2). Similar observations were explained by Basha and Rani (2003) as they reported that when the risk of oxidative damage increases, endogenous antioxidant protection also increases indicated by increased activity of catalase enzyme. However, Beigh et al. (2014) reported that dogs infected with dermatophytes had significantly lower plasma catalase levels when compared with control one. The plasma MDA level table (2) was significantly increased. Similar finding was obtained by Beigh et al. (2014) who reported a significant increase in plasma MDA values. The increased levels of plasma MDA was explained by Gurer et al. (1998) who reported that malonyldialdehyde is the most abundant aldehyde formed as a by-product during oxidative damage.

Dermatophytosis affected dogs revealed a high positive correlation between plasma $\mathrm{Zn}$ level and plasma $\mathrm{Cu}$ level, moderate positive correlation between plasma zinc level and plasma SOD level. Similar results were obtained by Beigh et al. (2014) who observed that SOD activity showed a positive correlation $(\mathrm{P}<0.05)$ with zinc and copper in both healthy and dermatophytosis affected dogs. AL-Qudah et al. (2011) reported that trace elements are required for the activity of a number of enzymes, including antioxidant enzymes. Ewans and Halliwell (2001) stated that copper along with zinc are essential components of the body's antioxidant defense like SOD. Additionally, Ighodaro \& Akinloye (2018) mentioned that SOD is a metalloenzyme and hence, requires a metal cofactor for its activity including iron, $\mathrm{Zn}$, $\mathrm{Cu}$ and Mangnese. A moderate positive correlation betw een plasma SOD and plasma GPx levels was recorded in dogs affected with dermatophytosis (table 3). Hefnawy \& El-Khaiat (2015) reported that $\mathrm{Cu}$ IZinc SOD catalyzes dismutation of the superoxide anion, producing molecular oxygen and hydrogen peroxide. The late product is usually metabolized by glutathione peroxidase and catalase which confirm the positive correlation between SOD and GPx in the present study. Fang et al. (2002) added that SOD catalyses the dismutation of superoxide radicals to hydrogen peroxide $(\mathrm{H}$ ${ }_{2} \mathrm{O}_{2}$ ), which is converted to $\mathrm{H}_{2} \mathrm{O}$ by catalase. 
Table (1): Blood Picture of Dermatophytosis Affected Dogs

Compared with Clinically Healthy

\begin{tabular}{|c|c|c|}
\hline Parameter & $\begin{array}{c}\text { Control } \\
(n=14) \\
(\text { Mean } \pm \text { SE })\end{array}$ & $\begin{array}{c}\text { Dermatophytosis } \\
(n=16) \\
(\text { Mean } \pm \text { SE) }\end{array}$ \\
\hline Hb (g/dl) & $14.86 \pm 0.53$ & $11.20 * * \pm 0.66$ \\
\hline PCV (\%) & $39.00 \pm 1.34$ & $33.91 * * \pm 1.60$ \\
\hline $\operatorname{RBCs}\left(10^{\wedge} 6 / \mu \mathrm{L}\right)$ & $5.98 \pm 0.25$ & $5.26^{*} \pm 0.24$ \\
\hline MCV (fL) & $67.28 \pm 2.25$ & $64.44 * * \pm 0.82$ \\
\hline MCHC (\%) & $38.15 \pm 2.31$ & $32.85 * \pm 0.88$ \\
\hline WBCs $\left(10^{\wedge} 3 / \mu \mathrm{L}\right)$ & $9.72 \pm 0.86$ & $16.16^{* *} \pm 1.37$ \\
\hline Granulocyte /cubic mm & $1.10 \pm 0.01$ & $4.8 * * \pm 0.06$ \\
\hline Lymphocyte /cubic mm & $7.01 \pm 0.05$ & $8.71^{*} \pm 0.08$ \\
\hline Monocyte/cubic mm & $0.65 \pm 0.01$ & $2.59 * * \pm 0.01$ \\
\hline
\end{tabular}

Table (2): Biochemical Findings of Dermatophytosis Affected Dogs Compared with Clinically Healthy Dogs.

\begin{tabular}{|c|c|c|}
\hline Parameter & $\begin{array}{c}\text { Control } \\
(\mathrm{n}=14) \\
(\text { Mean } \pm \text { SE }) \\
\end{array}$ & $\begin{array}{c}\text { Ring worm } \\
(\mathrm{n}=16) \\
(\mathrm{Mean} \pm \mathrm{SE})\end{array}$ \\
\hline $\mathrm{Zn}(\boldsymbol{\mu} / \mathbf{m l})$ & $0.822 \pm 0.040$ & $0.771 \pm 0.049$ \\
\hline $\mathrm{Cu}(\mu \mathrm{mole} / \mathrm{ml})$ & $0.087 \pm 0.012$ & $0.077 \pm 0.010$ \\
\hline Catalase (U/ml) & $0.289 \pm 0.020$ & $0.463^{*} \pm 0.034$ \\
\hline SOD (U/ml) & $2.280 \pm 0.170$ & $2.745 \pm 0.190$ \\
\hline GPx $(u / m l)$ & $0.212 \pm 0.014$ & $0.215 \pm 0.019$ \\
\hline MDA (nmole/L) & $0.212 \pm 0.014$ & $0.215^{*} \pm 0.019$ \\
\hline
\end{tabular}

$*$ Significance $p(0.05) * *$ Highly significance $p(0.01)$

Table (3) Correlation Between Trace Elements and Antioxidants of Dogs Affected with Dermatophytosis.

\begin{tabular}{|c|c|c|c|c|c|c|}
\hline & $\mathbf{Z n}$ & $\mathbf{C u}$ & CAT & SOD & GPX & MDA \\
\hline $\mathbf{Z n}$ & 1 & $0.844^{\mathrm{b}}$ & -0.194 & $0.653^{\mathrm{c}}$ & 0.394 & 0.006 \\
\hline $\mathbf{C u}$ & $0.884^{\mathrm{b}}$ & 1 & -0.176 & 0.324 & 0.281 & -0.163 \\
\hline CAT & -0.194 & -0.176 & 1 & 0.275 & 0.392 & 0.391 \\
\hline SOD & $0.653^{\mathrm{c}}$ & 0.324 & 0.275 & 1 & 0.508 & 0.398 \\
\hline GPx & 0.394 & 0.281 & 0.392 & $0.508^{\mathrm{c}}$ & 1 & 0.324 \\
\hline MDA & 0.006 & -0.163 & 0.391 & 0.398 & 0.324 & 1 \\
\hline
\end{tabular}

1- Very high positive/negative correlation (0.9 to 1.0)/(-1.0to 0.9)

2- High positive/negative correlation (0.7to0.9)/(-0.9to-0.7)

3- Moderate positive/negative correlation (0.5 to 0.7) /(-0.7 to -0.5) 


\section{References:}

Aebi H (1984). Catalasein vitro. In: Colowick SP, Kaplan NO (eds) Methods in enzymology, vol 105. Academic Press, New York, pp 121-126.

AL-Qudah, K.M., Gharaibeh, A.A., AL-Shyyab, M.M. (2011). Trace minerals status and antioxidant enzymes activities in calves with dermatophytosis. Biol. Trace Elem. Res. 136, 40-47.

Basha, P.S. and Rani, A.U. (2003). Cadmium induced antioxidant defense mech-anis $m$ in freshwater teleost Oreochromis mossambicus (Tilapia). Ecotoxicol. Environ. Saf. 56, 218-221.

Beigh, S. A., Soodan, J. S., Singh, R., Khan, A. M., \& Dar, M. A. (2014). Evaluation of trace elements, oxidant/antioxidant status, vitamin $\mathrm{C}$ and $\beta$-carotene in dogs with

dermatophytosis. Mycoses, 57(6 ), 358-365.

Birchard, S. J., \& She rding, R. G. (2005). Saunders Manual of Small Animal Practice-E-Book. Elsevier Health Sciences.

Bond R. (2010). Superficial Veterinary Mycoses. Clinics in Dermatology 2010; 28(2) 22636.

Chermette $R$, Ferreiro $L$ and Guillot J (2008).
Dermatophytoses in animals. Mycopathologia 166:385-405.

Ewans, P. and Halliwell, B. (2001). Micronutrients: oxidant/antioxidant status.Br. J. Nutr. 85, 57-74.

Fang, Y.-Z., Yang, S. and Wu, G. (2002). Free radicals, antioxidants and nutrition. Nutrition 18, 872-879.

Gaedigk A, Gaedigk $R$ and Abdel-Rahman SM. (2003). Genetic heterogeneity in the rRNA gene locus of Trichophyton tonsurans. J Clin Microbiol. 41:5478-87.

Gaskell, r. (1994). The skin in feline medicine and Therapeutic. $2^{\text {nd }}$ Edition. Blackwell Science Oxford, Uk, 3-83.

Gurer, H., Ozgunes, H., Neal, R., Spitz, D.R. and Ercal, N. (1998). Antioxidant effects of $\mathrm{N}$ acetyl cysteine and succimer in red blood cells from lead exposed rats. Toxicology 128, 181-189.

Hayakawa, R. (1961). Determination of zinc. Jap J Toxic Environ Health, 8, 14-18.

Hefnawy, A. E., \& El-Khaiat, H. M.(2015). The importance of copper and the effects of its deficiency and toxicity in animal health. International Journal of Livestock Research, 5(12), 1-20.

Houston, D. M. (2000). Clinical examination of dogs and cats. In: 
Radostits, O.M.; Mayhew, I.G.; and Houston, D.M.: Veterinary Clinical Examination and Diagnosis. W.B. Saunders, China, pp., 125-138.

Ighodaro, O. M., \& Akinlove, O. A. (2018). First line defense antioxidants-superoxide

dismutase (SOD), catalase (CAT) and glutathione peroxidase (GPX): Their fundamental role in the entire antioxidant defense grid. Alexandria Journal of Medicine, 54(4), 287-293.

Jaheen, A.H.R. (2015). Selected oxidative stress markers in stress related skin diseases of dogs. Unpublished master's thesis. Faculty of Veterinary Medicine, Cairo university.

Kerem, U.; Mehmet, C. K.; Ozkan, D.; Cenker, C.C.; Ali, E. and Havdardedeoğlu. (2009). Serum zinc concentrations in dogs with Microsporum canis dermatophytosis: a pilot study. Turk. J.Vet. Anim. Sci., 33(4): 279-283. doi:10.3906/vet-071120.

Lappin, M.R. (2018). update on flea and tick associated diseases of cayt.vet.Parasitol 254, 26-29.

Liu, D., Coloe, S., Baird, R., \& Pedersen, J. (2000). Application of PCR to the identification of dermatophyte fungi. Journal of medical microbiology, 49(6), 493-497.
Moriello K. A. (2004). Treatment of Dermatophytosis in Dogs and Cats: Review of Published Studies. Veterinary Dermatology; 15(2) 99-107.

Moriello K.A. and Ne wbury S. (2006). Recommendations for the Management and Treatment of Dermatophytosis in Animal Shelters. Veterinary Clinics of North America: Small Animal Practice; 36(1): 89-114.

Moriello, K. (2019). Dermatophytosis in cats and dogs: a practical guide to diagnosis and treatment. In Practice, 41(4), 138-147.

Mukaka M. M. (2012). Statistics corner: A guide to appropriate use of correlation coefficient in medical research. Malawi medical journal: the journal of Medical Association of Malawi, 24(3), 69-71.

Mulle r, G.H., Kirk, R.W., and Scott, D. W. (1989). Cutaneous parasitology. In Small Animal Dermatology. W.B. Sanders Company: P. 347-426.

Nair, S. S., \& Naurival, D. S. (2007). Diagnostic significance of haematological changes associated with various canine dermatoses. Intas polivet, 8(1), 68-72.

Nishikimi M, Roa NA and Yagi $K$ (1972). The occurrence of superoxide anion in the reaction of reduced 
phenazinemethosulfate and molecular oxygen. Biochem Biophys Res Commun 46:849854.

Ohkawa H, N Ohishi and K Yagi (1979). Assay of lipid peroxides in animal tissues by thiobarbituric acid reaction, Annals of Biochemistry. (95):351-358.

Okayama, Y. (2005). Oxidative stress in allergic and inflammatory skin diseases. Current Drug TargetsInflammation \& Allergy, 4(4), 517-519.

Oute rbridge, C. A. (2006). Mycologic disorders of the skin. Clinical techniques in small animal practice, 21(3), 128-134.

Paglia, D.E. and Valentine, W. N. (1967). Studies on the quantitative and qualitative characterization of erythrocyte glutathione peroxidase. $\mathrm{J}$ lab Clin Med.70:158-169.

Paterson, S. (2019).

Dermatophytosis case bookcommon impersonators and atypical presentations. In BSAVA Congress Proceedings 2019 (pp. 54-54). BSAVA Library.

Putriningsih, P., \& Arientinia, I. (2017). Macroconidia of dermatophytes fungi on direct microscopic examinations. Journal of Veterinary Medicine and Animal Science, 1(1), 40-2.
Sindha, M. J., Trangadia, B.J., Vihol, P. D., Parmar, R. S., \& Patel, B. V. (2015). Clinicopathological evaluation of non-parasitic dermatoses in canines. Veterinary world, 8(11), 1346.

Singh, S. K., Dimri, U., Sharma, M. C., Swarup, D., \& Sharma, B. (2011). Determination of oxidative status and apoptosis in peripheral blood of dogs with sarcoptic mange. Veterinary parasitology, 178(3-4), 330-338.

Stockham S.L.; Keeton K.S. and Szladovits B. (2003). Clinical assessment of leukocytosis: distinguishing, glucocorticoids, physiologic and leukemic disorders or conditions. Journal vet. Clinical of small animal 33, p: 1335 1357.

Ural, K., Karakurum, M. Ç., Duru, O., Cingi, C. C., \& Haydardede oğlu, A. E. (2009). Serum zinc concentrations in dogs with Microsporum canis dermatophytosis: a pilot study. Turkish Journal of Veterinary and Animal Sciences, 33(4), 279-283.

Ventura S. and King, E.J. (1951). Biochem. J. 48 IXI= Eden A. Green HH. (1940). Biochem. J. 34: 1202. 


\section{دراسات اكلينيكية ومعملية مع الارتباط بمؤشرات الإجهاد التأكسدي في فطار

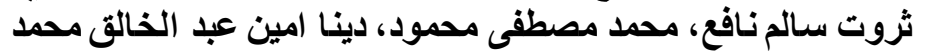

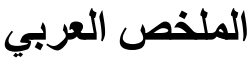

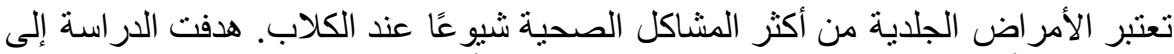

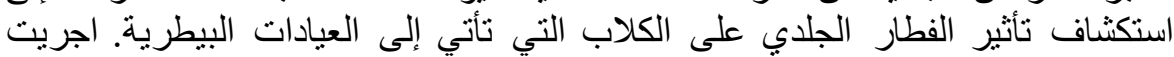

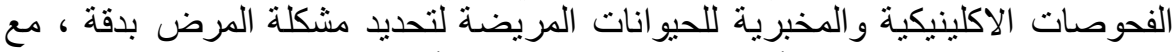

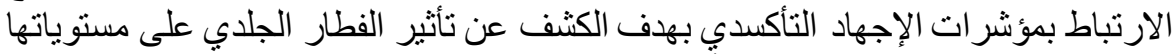

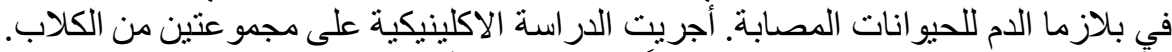

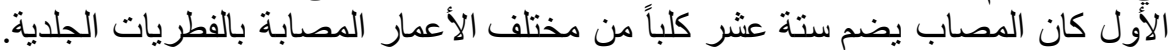

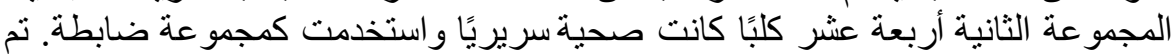

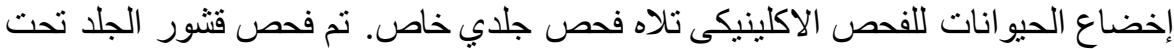

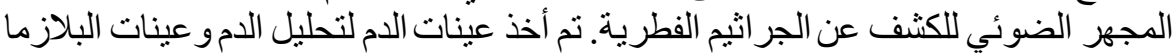

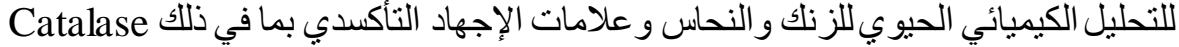

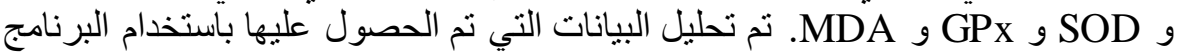

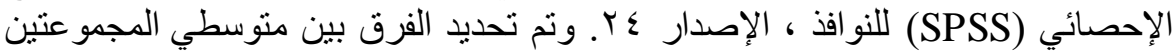

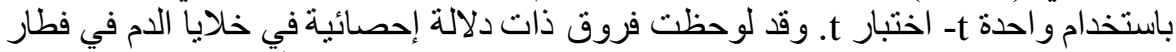

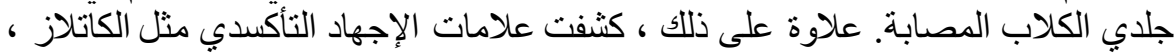

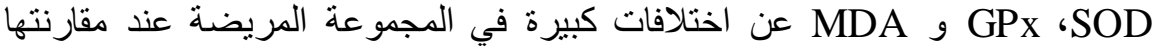

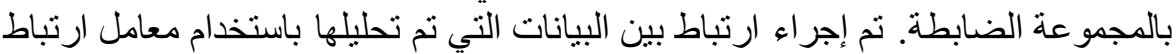

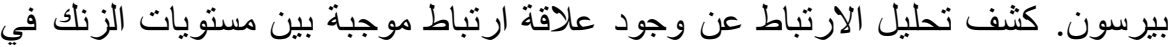

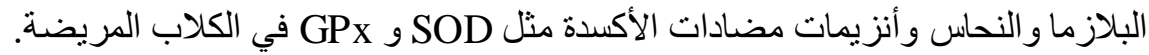

